\title{
Community Engagement and Service Learning: Putting Faces to a Commu- nity to Create Better Engineers
}

\section{Dr. Kathryn Schulte Grahame, Northeastern University}

Dr. Kathryn Schulte Grahame is an Associate Teaching Professor at Northeastern University and a member of the first-year engineering team. The focus of this team is on providing a consistent, comprehensive, and constructive educational experience that endorses the student-centered, professional and practiceoriented mission of Northeastern University. She teaches the Cornerstone of Engineering courses to firstyear students as well as courses within the Civil and Environmental Engineering Department. She is a recent recipient of the Outstanding Teacher of First-Year Students Award and is interested in research that compliments and informs her teaching.

\section{Dr. Susan F. Freeman, Northeastern University}

Susan Freeman, is a member of Northeastern University's first-year engineering facutly, a group of teaching faculty expressly devoted to the first-year Engineering Program at Northeastern University. The focus of this team is on providing a consistent, comprehensive, and constructive educational experience that endorses the student-centered, professional and practice-oriented mission of Northeastern University.

\section{Mr. Jake Alexander Levi, Northeastern University}

I am a Computer Engineering \& Computer Science student at Northeastern University. 


\title{
Community Engagement and Service-Learning: Putting faces to a community to create better engineers
}

\begin{abstract}
This complete evidence-based practice paper presents how Service-Learning (S-L) helped firstyear engineering students attending an urban institution to grow their concept of community. When S-L is incorporated into a first-year engineering design course, students expand their learning as they work and teach in the community. In addition, students get a chance to see and experience the greater community to which they belong. Through S-L, engineering students also learn about social issues and societal norms outside of the immediate boundaries of their university. This work aims to assess the level of our students' presumptions of the surrounding communities, both before and after a S-L opportunity and presents evidence of students' growth towards a more open mindset.
\end{abstract}

First-year engineering students enrolled in a S-L section of an engineering design course at Northeastern University are required to complete mandatory service with community partners outside of class hours as part of their course assessment. Two instructors of the design course, Cornerstone of Engineering, added an additional element of S-L to their course to allow over 120 students this additional growth opportunity. Over $15 \mathrm{~S}-\mathrm{L}$ sites were included in the community partnerships with two main foci: middle school robotics leagues and a community makerspace.

Two surveys (Pre and Post course) helped to identify initial impressions and changes in students' (1) understanding of community partner's geographic location, (2) impressions of location, (3) propensity to frequent a business in that location, and (4) knowledge of actual persons residing in the community. Students were asked to write reflections after S-L site visits which acted as assessments of their growth in understanding of course concepts. The reflections were also useful to see the students' perception of professional growth and their perception of the community and their impact on it.

Initial surveys indicated that news and word of mouth stories played a large role in students' impressions of the surrounding neighborhoods. As expected, the majority of students had not frequented a business or even ventured into the neighborhood, despite its close proximity to campus. Students frequently answered questions with an emotional distance between themselves and statements about the neighborhood. During the semester, reflection entries generally showed the majority of students reporting seeing the community differently, with significantly less negative commentary. After the course, they know people in the surrounding urban community and are more likely to frequent businesses there. After S-L the students start to lose the concept that the surrounding urban community is distinct from the university community. We conclude that the S-L opportunity forces our students out of their comfort zone, helping them to grow as engineers who are better prepared for future challenges. 


\section{Introduction}

At Northeastern University, located in the heart of Boston, MA, first-year engineering students are required to take a series of two courses known as Cornerstone of Engineering. In these courses, students learn programming, graphical design, problem solving and follow the engineering design process to create final projects that integrate all of their newly learned skills. While there are many engineering skills directly taught in this course, there are many 'soft skills' such as empathy, professionalism, and adaptability that are indirectly taught along the way. These skills are not assessed by any direct measurement, but are nonetheless important for success in an engineering career. They can usually only be achieved through practice and experience.

Service-learning (S-L) is both a form of experiential learning for students and a teaching tool for faculty. Students in S-L courses partner with community-based organizations as a way to learn the course material with a fresher and more informed perspective while meeting and serving community needs. Faculty who teach S-L courses are able to integrate classroom and community goals resulting in an enrichment of their course experience, lifelong community bonds and engagement for their students, and strengthening local and global communities. In the case of the Cornerstone course, the S-L partnerships provide our students the opportunity to experience the greater urban community to which they belong. By doing so, they also have the chance to utilize these experiences in context through service, resulting in a deepening and growing of their own engineering skillset.

At this institution, two instructors created four S-L sections of the Cornerstone course. The 120 students enrolled in the S-L sections were required to complete service with community partners outside of class hours as part of their course Over $15 \mathrm{~S}$-L sites were included in the community partnerships with two main foci: middle school robotics programs or assisting in a community makerspace. Students were expected to travel to the sites on their own, which were just outside the immediate university boundaries, and interact with the youth in various STEM related activities. With many of our students coming from affluent suburban communities, there was a lot of room for growth in learning about their new neighbors.

The question driving this work is: does S-L help first-year engineering students attending an urban institution grow their concept of community? This work aims to assess our students' presumptions of the surrounding urban community both before and after an S-L opportunity and presents evidence of students' growth. 


\section{Background}

To set the backdrop of the S-L experience, there is some history and context needed. The Cornerstone of Engineering course is a project based course, and all sections have engineering themes to guide the projects. Two of the sections are robotics themed, where students build, design, and program robots as they are learning engineering design, programming and graphics. As S-L students, they are going to after school sites in the local community and doing similar activities with middle school students. They are learning and teaching the skills each week from class. The instructor has been partnering with several organizations for the past 7 years, and works with these partners closely to align the learning objectives of the course for the students to the objectives of the community partner. Previous papers have described these engineering S-L experiences. [1] [2] In the other two sections of the Cornerstone course it is a Sustainability theme. Their project requires constructing a working interactive display. These students applied and learned more build and design skills by helping in a makerspace.

All requests for partnerships came through S-L at Northeastern University. Similar efforts for S$\mathrm{L}$ in STEM are ongoing as evidenced in 2 recent papers presented at the ASEE conference in 2018. [3] [4] Both instructors have focused on Asset Based Community Development principles in their approach to engineering S-L [5]. The definition of S-L can come from many sources, but a frequently encountered one is from Janet Eyler and Dwight Giles - "a form of experiential education where learning occurs through a cycle of action and reflection as students. . seek to achieve real objectives for the community and deeper understanding and skills for themselves. In the process, students link personal and social development with academic and cognitive development. . . experience enhances understanding; understanding leads to more effective action." [6] The instructors have worked with all of the students that are participating in the S-L on following the steps in this cycle to achieve many facets of development for the students and the community partners. One aspect is discussed in this paper, concerning the student perception of the community.

\section{Literature Review}

There is a considerable amount of literature addressing the positive impact of S-L on students with some on the effects on faculty and the community. Included here are some of those works, including some that focus on S-L in urban settings. There is also literature on $\mathrm{S}$-L in engineering contexts, and even first-year engineering, which are also included here. There is a smaller set of literature that discusses students' involvement in an urban community, and the perception and impact on students. The progression in this paper will go from general, to engineering, to urban settings to set the stage of this paper and work. An extensive paper by Janet Eyler, et al contains a large volume of papers that support the positive effects of S-L on many constituencies. It is a compilation of organized research studies on S-L, with sections: Effects of Service-Learning on: Students, Faculty, Universities, and Communities. Some of the studies are objective in considering both positive and negative effects such as looking at student learning as not being ubiquitous in improving grades, but most studies clearly show improvement in professional skills, leadership skills, connection to the community of the university, increased likelihood to continue community service after graduation with additional positive effects on the community, faculty and university. Overall, these studies build a case for the many positive impacts of S-L. [6] 
An article by Grace Ngai [7] focused on outcomes for student learning due to participation in SL. Basing their work and findings on several premises, particularly that S-L is a high impact practice [8], many sections discussed the challenges for positive learning outcomes for students, but clearly guide faculty to plan carefully, as it is not just doing S-L, but how and what students learn depends on the quality achieved. The goal in this work was to consider that the type of neighborhood could have a positive, negative or neutral effect on learning and students' perception and continued interest in community service.

Even in 2006, the idea that the hallmark of S-L was its focus on relationship and reciprocity was becoming recognized. [9] Though not the main focus of this work, being able to really give and take requires knowledge, comfort, closeness and acceptance, which may come if students feel like they are a part of the neighborhood, rather than merely visitors. By this method, the students and faculty build strong, two way relationships and reciprocity that work to benefit both parties.

The identity status paradigm is used to understand the effect of S-L on future plans for students of varying identity statuses, as can be seen in work done by Pelco and Ball. [10] This paper is not measuring this identity status, but is linked - in that there may be a correlation. If students' connect more to their community, does it influence the degree of benefits they perceive and possibly make them more likely to continue? Their study found that students across all identity status groups indicate that their S-L experiences helped them to clarify future plans, and that community partners can leverage these opportunities. Potentially, students can see future career or volunteer roles and can become more engaged volunteers and citizens through service. Thoughts for future research could investigate: the possibility of future roles being tied to the community and community partner, whether the type of service completed is impacted by the incoming identity status, and whether there is growth in identity during service.

Campus Compact [11] is known for their studies in S-L, and this one contains a great summary of what has made partnerships truly good and successful for all stakeholders. The paper walks through the process, the research, and the practicalities of how to build successful partnerships and research in S-L. A set of great lists allow us to look for where we have done well or what we need to strive for. Both Effective Partnerships and Best Practices of Campus-Community Partnerships contain such critical aspects as goals in the ongoing work such as: ensuring that communication is clear and ongoing, understanding one another's organizations via mutual goals, proper planning (including training, orientation, and preparation), and focus on students with regard to placement fit. It is also key to have: continuous assessment of partnership process and outcomes. With this paper focused on understanding, in particular the Roxbury neighborhood, this also connects to understanding the partner's needs, what the shared goals are and the context for those goals. Budhal and Grant [12] add to this by providing insights on preparing students, being organized, clear expectations, communication and other important characteristics of reciprocal and impactful S-L that create impressions, both initial and lasting ones, with good lessons and impactful takeaways for continual improvement.

The research by Simonet [13] on S-L validates a long-standing philosophy that integrating academics and community service delivers greater student leadership development, enriched learning, and improved academic performance. It provides evidence of S-L's benefits to the theoretical explanations of student retention, and gives a clearer vision of how each field may 
enhance the other. It argues that S-L should be thought of as a process that creates greater student engagement, which in turn results in the product of student retention. The overall intent is to provide a clearer foundation in the research that supports the way that S-L is related to student success and therefore retention. In lists of recommended practice, a few items standout such as designing S-L to maximize the number of meaningful interactions amongst individuals from diverse backgrounds. Many of our students remark on the diversity as they venture out of the university enclave. Another clear connection is building S-L into the freshman year to quickly establish community connections and a diverse campus. These support the S-L programs established at Northeastern University in the first-year. Some work reviewed looked promising to connect and inform, such as [14], but although it is engineering, little else applies as it is mostly international and focusses on meeting objectives, what the students learn about engineering, without much reflection on how they interacted with their community partners.

To continue the connections to engineering, engineering educators have already established successful S-L programs with first-year engineering students at other universities. [15] [16] [17]. There are also S-L projects for first-year engineering students involve K-12 outreach. [18] Even more connected is a case study look at engineering undergraduates in Rupnow et al. [19] This was an in depth study of engineers, as cases on $6 \mathrm{~S}-\mathrm{L}$ students. Significant here, is the concept that students learned about their communities, which motivated them to think about their own homes in different contexts. As some of these experiences were not in urban contexts, it is not directly correlated, but can still provide some insight. They identified motivation, learning, and perspectives as major themes in engineering students' service experiences. Students learned about the communities they were serving, which motivated them to think about their own homes in different social, political, cultural, and economic contexts. Participants also described a sustaining motivation to join future S-L or community service trips. Their underlying framework is in transformation theory, far deeper than this work, but is great for aspirational research ideas.

As the focus on this work is students being affected by their urban communities, it is helpful to look at some of the work by Bringle and Hatcher, who have contributed so much to the field and research. This quote really ties together all of the complex pieces involved, along with mentioning urban universities - "Students are in a paradoxical position with regard to service activities. On the one hand, some students are involved in voluntary service through campus organizations. Campus Compact provides ample evidence of the vigor that student-initiated and student-led service programs can display. Furthermore, urban universities have a sizable portion of nontraditional students who are actively involved in their communities independent of the campus. On the other hand, students are dependent upon others for $S$-L opportunities. $S-L$ typically occurs only if a faculty member develops a $S$-L course, the course is approved, the course is offered, and the course is appropriate for a student (e.g., meets degree requirements, prerequisites). Faculty are also dependent upon students in that a $S$-L course will only be successful and repeated if students enroll in the course and if it results in a successful educational experience." [20]

In this urban university setting for S-L, we can look to an article meant to spur discussion and controversy. [21] Pertinent to this work is the concept that S-L can do harm in a community, for example, students just "passing through", either literally or figuratively, can have negative effects. Not seeing the neighborhood, and possibly being negative in some way, is a simple 
example. In relationships, community participants may form relationships that seem fine to a college student, but too short and one sided to a community member. To ameliorate this, students need to understand social structural issues. As the faculty involved work more in this community, we can continue to try and improve our students' view of social change, community issues and social structure around them, instead placing of too much focus on the effects on them and who they are.

In work by Maurrasse [22] the introduction clearly lays out a case that the fate of communities is the fate of the universities. In urban areas that have come upon hard economic times, colleges and universities remain. At first, they blockaded and protected themselves, but more recently, the movement is to connect and when done correctly, both can flourish. This cannot be paternalistic, or "helping" mentality, but true partnerships (see [21]). There are cases of this successful partnerships, which entwine the blighted community with an academic partner for growth and success. In an article from Inside Higher Education [23], the discussion centers on urban universities having lower graduation rates, and not fulfilling their roles in the community to serve the students from there. Therefore, S-L practitioners from Northeastern are part of a larger problem where students from our lower income communities either are not admitted or flounder at our schools, and the schools do not shoulder enough of the blame, so that there is a quiet crisis of urban higher education and much of the best work of $\mathrm{K}-12$ reformers will come to little success. Northeastern is part of this reformation; giving up is not the solution, but rather being cognizant of this larger problem and taking steps to ameliorate it when the opportunity arises.

Engineering outreach can branch in many directions, one being increasing the number of women entering STEM fields. This prompts some further thoughts for more research on effects for both women engineering students and girls in outreach from local schools. The paper by Portsmore and Swenson provide sound guidance for how to be most effective. [24] In another engineering approach in an urban setting, Epstein et al. [25] mention an urban context, though are not clear on the socioeconomic makeup of the area. The dissimilarities in programs are more prominent than the similarities. There is not much data on the neighborhood, and the program was moved and housed at the University, which creates a very different dynamic. The reciprocal partnership is well managed and clearly ongoing growth is happening, which is similar. The connection here is really that S-L exists in other urban pockets and engineering students have a variety of roles for mentoring. Many lessons they have learned are instrumental for any workers in the field.

For more closely aligned urban context, Ratcliff and Fuehne [26] have many connections. Here, Purdue is going to an urban neighborhood and using Lego Pulley sets to introduce engineering and STEM. They run workshops with $4^{\text {th }}, 5^{\text {th }}$ and $6^{\text {th }}$ graders. Common here are the age groups, using Lego to introduce STEM, engineering students leading activities and repeated visits. In addition, it is likely that most of the students in the communities are similar, although this was not tracked directly. In this paper, at-risk students were those eligible for free lunch. In the Roxbury neighborhood where all of these S-L students are going to, $80 \%$ or more of the students are eligible as published on the Boston Public School's website [27] and in a national database for metrics on school districts [28]. The paper focuses on the activities used, and some scoring of the kids in the program, not on S-L student feedback or impacts. It has helpful ideas and information to guide other practitioners, but not information on interfacing with the 
neighborhood. Another helpful work because of the urban context is in a different field, architecture, where they discuss three facets of successful S-L partnerships, students, faculty and community. [29] Most of the discussion of students and faculty have similar cautions and advice as in much S-L literature, and not the focus of our work. There are some salient points on working with the community, which will continue to drive us. Universities can provide useful labor, a set of skills and access to expertise they might not have in an urban neighborhood, as long as there is care taken to remember the skill level of the students, the limited resources even of a university and to embark on reciprocal partnerships, the result can bring many gains to the neighborhoods.

The most surprising and influential work was from the field of geography in an article by Elwood [30], the context is in a geography course, but the insights and analysis are very related and were impactful to review and think about how to move in good directions from what these authors have found. The author found that learning through experiential practices in their course is shaped by the existing knowledge and conceptual frameworks that students hold about urban places, formed by what they see as urban, and tied to their conceptions about a specific neighborhood in a particular city. This paper has narratives where students describe and dig into their impressions, their misconceptions and changed viewpoints that were impacted by their S-L experiences. The paper describes narrative written before even entering an urban area are shaped by students' identities, life experiences, family histories, and urban, rural, and suburban places of residence. Then the paper offers strategies for using experiential pedagogy to foster critical thinking, toward a goal of creating "critical citizens who are able to exercise power over their own lives and especially over the conditions of knowledge production and acquisition." (quote from Giroux [31])

In summary, this is an effective look through some literature guided core practices of S-L, through the perspective of maximizing the benefits for students, faculty and the community. Engineering S-L further provided good practice ideas and continued ideas for effective work. Understanding the urban setting and the perceived effect on students continues to be a question, where much of this work raises further questions and clearly emphasizes that every S-L experience must be assessed and reviewed through reflections and other instruments to continue to grow and improve.

\section{Methodology}

To deepen students' understanding with experiential learning, two instructors at an urban university brought S-L to their first-year engineering course. This entailed students completing mandatory service with community partners in addition to their course load. Over $15 \mathrm{~S}-\mathrm{L}$ sites were included in the community partnerships with two distinct charges: middle school robotics leagues or community makerspace. Students signed up for shifts at the sites based on their available hours outside of normal class meeting times. At the sites, university students were tasked with engaging with community members - who were either middle school or high school aged children, depending on the site. As part of the urban university's S-L goals, both the community partner and the participating course must have a set of mutually beneficial goals. Having university students at the sites benefited the community partners through facilitated STEM engagement, strengthening community bond, and the provision of role models who 
facilitated learning. Our learning goals for our students were: to experience the culture of the urban community which they live in, to learn about its people - their neighbors - in a genuine and meaningful way, and to utilize their interactions to inform their work to create products that were more client focused.

To measure initial student impressions of their community and its members, a survey was administered to our students at the beginning of the course. Questions aimed to identify students' (1) understanding of community partner's geographic location, (2) impressions of location, (3) propensity to frequent a business in that location, and (4) knowledge of actual persons residing in the community. Based on the pre-assessment data, S-L Teaching Assistants (S-LTAs) tailored mini lectures and in-class activities to help students understand their role as a community volunteer and in the larger city community. University students were asked to write reflections after S-L site visits for assessment that comprised part of their course grade. S-LTA's assessed these reflections by looking for students': acknowledgement of S-L's relationship to course concepts, perception of professional growth, and their perception of the impact on the community.

To measure how student impressions of their community and its members changed through this S-L enhanced course, a survey was administered to our students at the completion of the course. The same questions were asked and it was our aim to look for any perception changes gained through the S-L experience.

\section{Results and Discussion}

We received a $72 \%$ response rate; there were 86 respondents for our survey, but over 120 students were offered the opportunity. Although they are in S-L classes this was not an assignment; the survey was voluntary and optional. 


\section{1) What do you know about the location of Roxbury?:}

These results (presented in Figures 1 and 2) show two main things. Firstly, that by participating in S-L, $23.5 \%$ of students had enough of a positive experience to note it when asked about the location of Roxbury. Secondly, the number of people who had no idea where Roxbury was dropped substantially, from $41.1 \%$ to $3.7 \%$. A large number of responses also mentioned other factors, such as socioeconomics, or businesses.

Additionally, the number of students who felt the area was dangerous, or 'sketchy', decreased from $11.6 \%$ to $7.4 \%$.

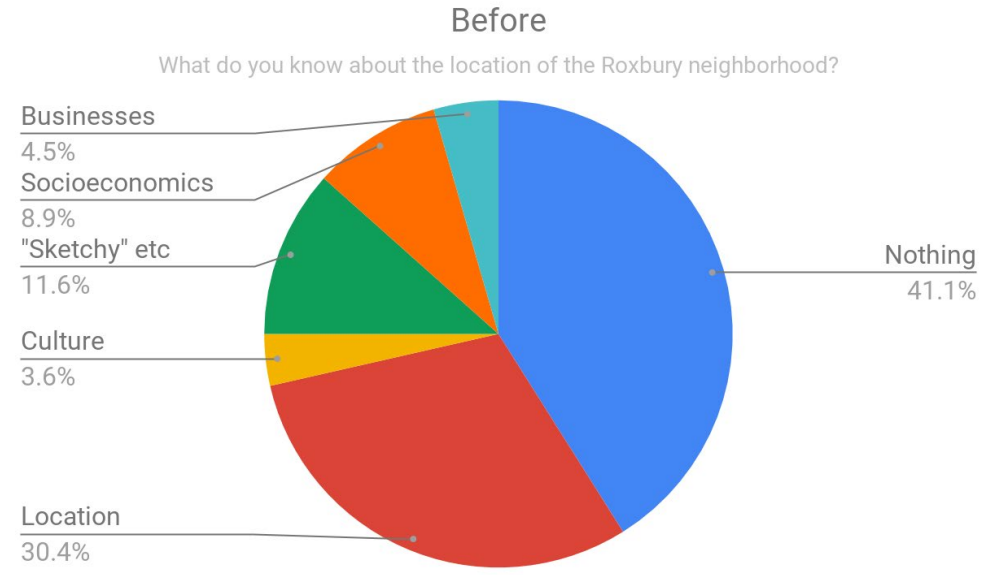

Figure 1 - Pre S-L responses: What do you know about the location of the Roxbury neighborhood?

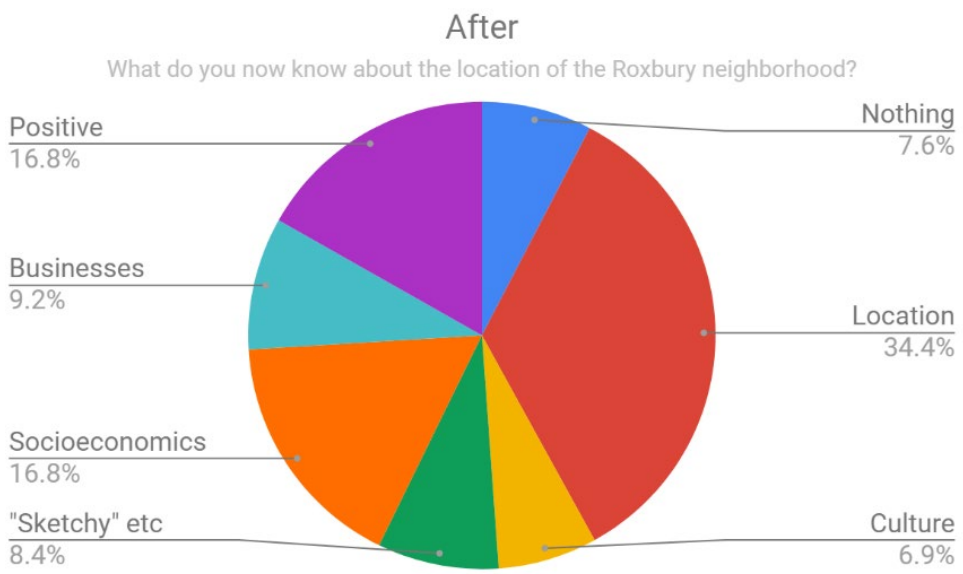

Figure 2 - Post S-L responses: What do you know about the location of the Roxbury neighborhood? 


\section{2) Do you know any people who live in the Roxbury neighborhood? What is their relationship to you?}

This question (presented graphically by Figures 3-4) demonstrates that most students gained enough of a connection to the area whilst participating in S-L to say that they personally knew people in the neighborhood. Between the first and second surveys, (roughly 3 months of site visits) $38 \%$ more students reported that they knew someone form the neighborhood. The reported relationships changed from a small number of friends to the constituents and families living in this community.

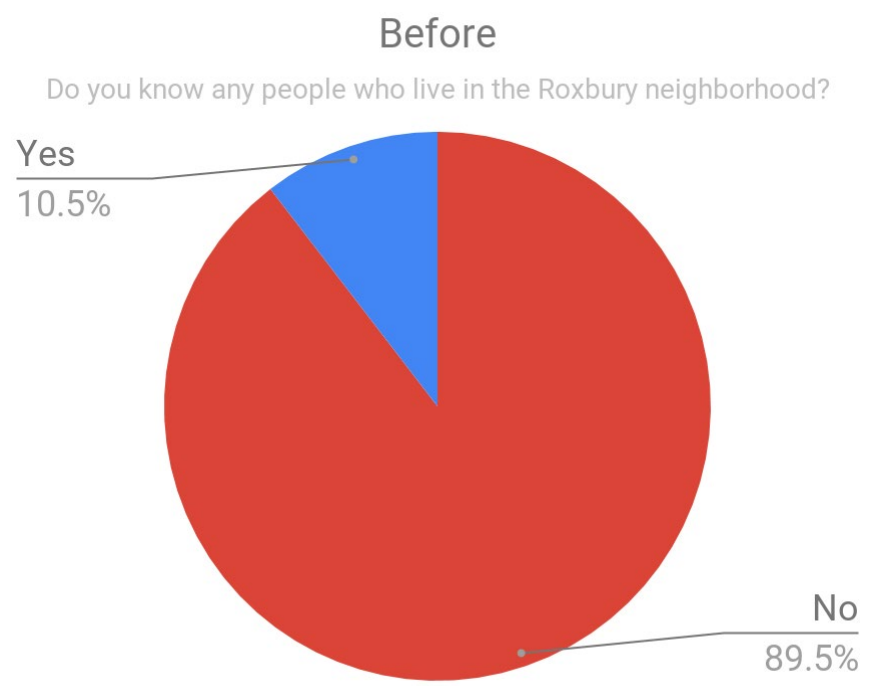

Figure 3- Pre S-L responses: Do you know anyone living in the Roxbury neighborhood?

\section{After}

Do you know any people who live in the Roxbury neighborhood?...

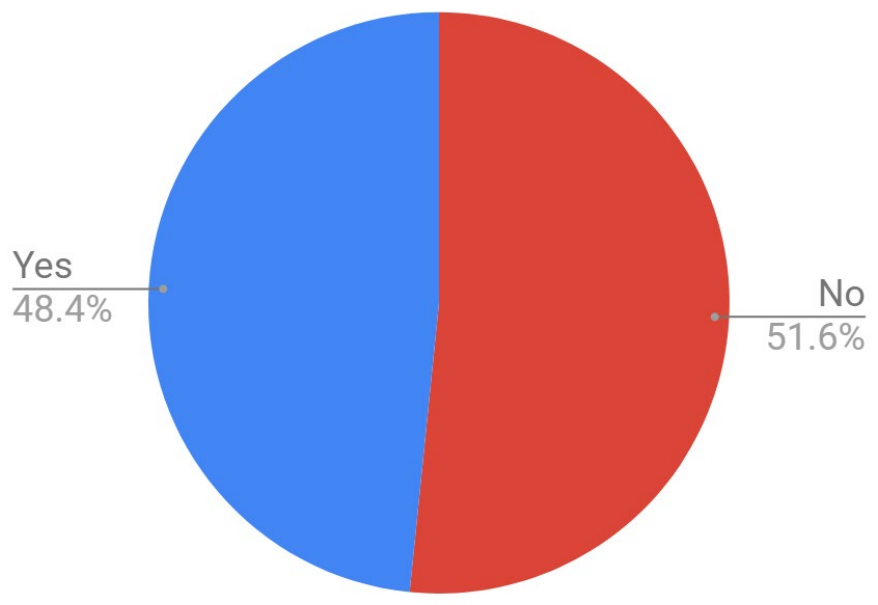

Figure 4 - Post S-L responses: Do you know anyone living in the Roxbury neighborhood? 


\section{3) Have you heard any stories about Roxbury? What were they?}

This question shows that some negative opinions still exist about the surrounding community. However, the data (presented in Figures 5-6) show positive stories emerge which was not there before. The urban context of this work and the safety aspect of traveling in a city must be considered when evaluating the student opinions. The students increase in some of the less favorable topics may be because they now know about the community, and are tuned into information on the area. No personal negative stories emerged, and students did not report being concerned. The growth comes in knowledge of the community, good and bad.

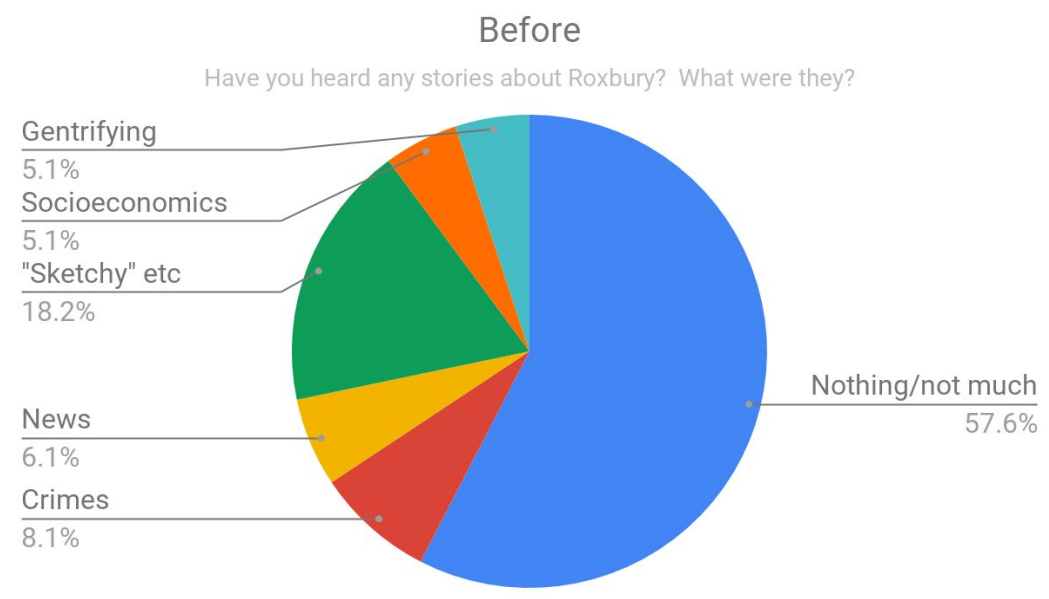

Figure 5- Pre S-L responses: Have you heard any stories about Roxbury? What were they?

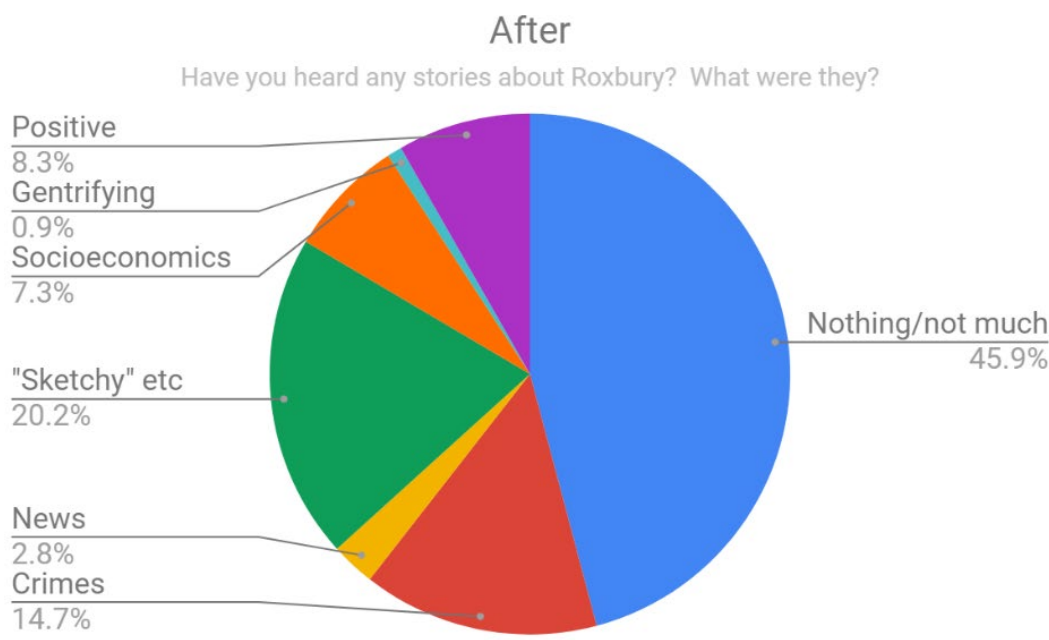

Figure 6 - Post S-L responses: Have you heard any stories about Roxbury? What are they? 


\section{4) What are your current impressions of Roxbury?}

These results (presented in Figures 7-8) were the most promising section out of all questions, as they show a huge shift in the opinions of the students. Before participating in S-L, no students had a positive impression of Roxbury. After participating in S-L, $34.9 \%$ of students had an assuredly positive opinion, and a reading of the responses show that even if the students did not feel positively towards the neighborhood, they understood the area as socioeconomically troubled, and would not feel safe walking alone at night. However, this is a striking difference from the pre-surveys, where most students had responded in ways that indicated they never would set foot in the area because of its criminal reputation, which is a product of the sensationalized rumors and stories surrounding Roxbury.

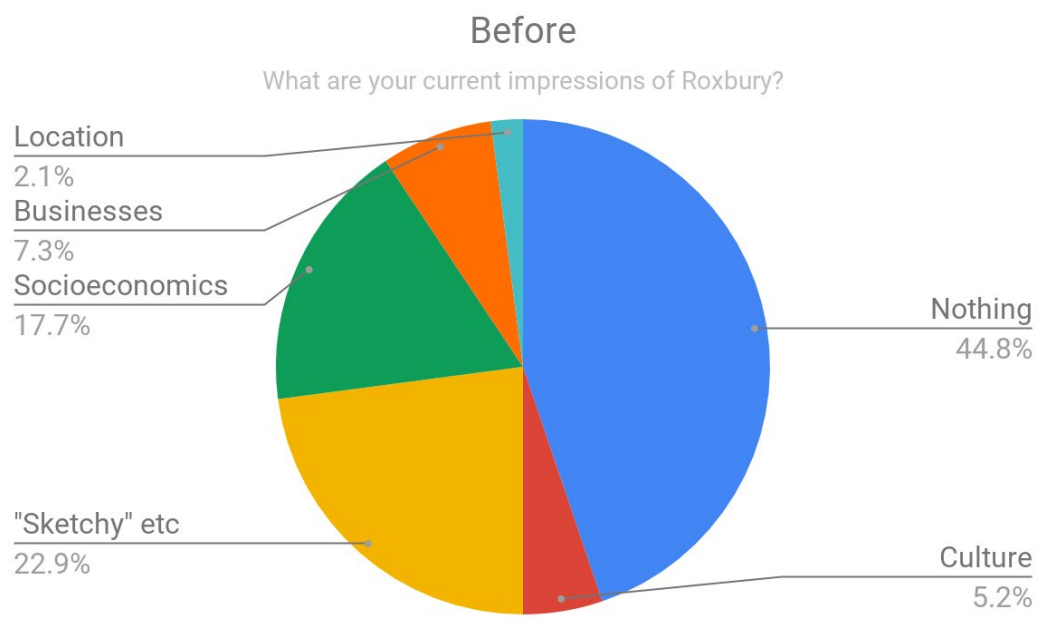

Figure 7- Pre S-L responses: What are your current impressions of Roxbury?

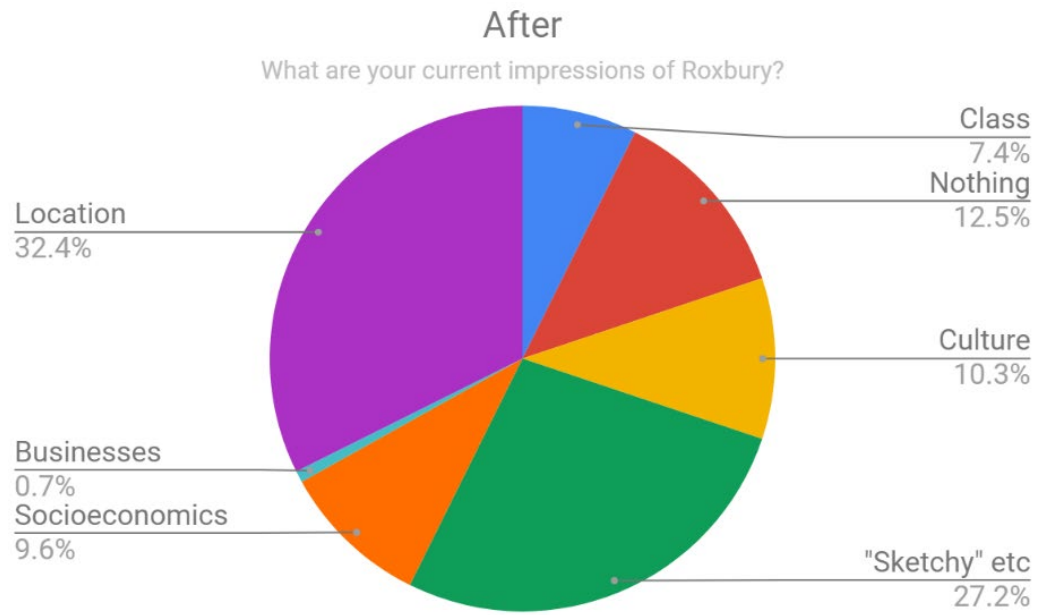

Figure 8 - Post S-L responses: What are your current impressions of Roxbury? 


\section{Selected quotes from the post survey that sum up the average experience:}

"I think Roxbury is a little rough around the edges, but a pretty good place in all."

"Because of the time that I spent in Roxbury, I learned that though there are some bad areas, there are also many community assets that make it a nice place to go. There are many restaurants and shops, playgrounds, and community centers. It generally has a bad reputation, but it is improving. “

"I don't think Roxbury is as bad of an area as everyone portrays it to be. I never felt in danger when I was walking to the Clubhouse."

\section{Selected quotes from the post survey that sum up the positive experience:}

My impressions of Roxbury definitely improved from the beginning of the semester. I realize now that it is not nearly as dangerous as I initially thought. I definitely have a positive impression of the community now.

Roxbury was not as dangerous or "scary" as other people made me believe it was (as previously discussed). It had a lot more organizations and built-up areas than I thought it might, and I have not had any problems traveling between Roxbury and campus.

My current impression of Roxbury is that it is generally not the safest neighborhood, but it is not as bad as everyone makes it out to be. I think that there are plenty of nice people, and I think that people there do not have as much opportunity to resources as I did growing up.

Although the people of Roxbury are certainly less privileged, all of the people I have met have been extremely friendly and welcoming. It is a nice neighborhood with good people.

\section{Selected quotes from the post survey that sum up the negative experience (these were the minority):}

It seems to be a poorer area and there really isn't anything there that would bring me there except for the Clubhouse.

I would try to avoid Roxbury, even after visiting the Clubhouse. It was uncomfortable as it got darker, for there were certainly some shady areas and the occasional suspicious person. I would have no need to go since Northeastern itself contains anything I could ever get from Roxbury. There are certainly great people just looking to make a living, but it's not worth the risk to go.

Honestly, it's a pretty cool place aside from the crime.

Less than positive, it's an area I likely would not want to be wandering around alone at night. 


\section{Quotes from Service-Learning Reflections}

As described in S-L literature, [20] reflections by the students are key components of good practice. The reflections done pre-, during and post S-L were not explicitly focused on the students' perception of the community. Nonetheless, these reflections impart more to the story of how they see the community and how connected they now feel to this community.

These quotes talk about connecting and even bonding with students' in the community.

I really bonded with the girls I worked with last semester. OJ

Service-Learning was an entirely new experience for me. I enjoyed it and willing to keep being involved in the life of the community that surrounds me through my education. I learn more about Boston and American culture from those kids than from two years of American history classes. They showed me new ways of looking at ordinary objects one example for this would be magnetic shoes that I would have never thought about). I also realized that learning is not always about the book and equations. Sometimes there are better ways, like getting out and helping, teaching people who deserved the knowledge. Even though it is not evident from a first glance, but teaching is the best way to learn. When you explain the concept to an 11-12 years old kid, you need the most fundamental understating of the process to be logical. Working with kids gives you an opportunity to dive deeper into what you have learned during the class. OL, from Ukraine.

I learned that some kids will have good days and bad days, some will be consistently distracted, and some will be consistently engaged and actively participating. Meeting every kid where they are at in that particular moment and understanding them is key to helping them through the activities and projects. Even for me, at times I was extremely tired by that time of the day, but the kids motivated me to be my best, and for this semester, I will continue to take that motivation to be a good role model for the kids and teach them more about robotics and about life. $\boldsymbol{E M}$

Throughout this process I also wanted to make connections with people in my community, and I got to know student 1 very well and this made me very happy. Every time I would go to service learning after having a tough and tiring day, I knew I would find inspiration in the excitement of the kids. They were constantly entertained and attentive when it came to their robots, and this reinforced my interest in technology and having it be such a large part of my career. $\boldsymbol{A M}$

From the concrete experience of going to Boston and mentoring the children at Orchard Gardens, I learned a lot about the community and the experiences of the students. Many had not been exposed to robotics or engineering before, which I was not expecting. I had to adjust to them having little background, but being willing to learn new things. I also learned how to work with the supervisors. $G \boldsymbol{B}$

One thing I learned that was key with service learning that I will hope to continue to do in my future service learning is form relationships with the kids. I personally liked asking the kids how there day was and getting to know them and listening to the life of a middle 
schooler and their daily dramas for I think it made our connections stronger and easier when it came to working with them.... I think connecting with the kids and their interests and what's poppin in the the younger kids culture of today would help build a stronger relationship with the kids. $\boldsymbol{R P}$

What stands out about this comment from a reflection is the concept of impact, of family ties and that he could be describing any children. He was not talking about them as if they were somehow "different", and his passion for working with the program is clear.

As we spent more time getting to know the families, the time spent at the site started to feel different; it started to become less about the competition, and more about the experience. The wonder and amazement in the kids' eyes, the way they cheered for their robots, and their tenacity was truly inspiring. It helped me see the broader impact of what we were doing. It was more than just teaching robotics fundamentals, we were supporting the passions of intelligent children and involved parents. JD

The next piece really sums up much of what we hope for the students: the S-L experience affects a change, and they see themselves differently and can articulate it. Many of the reflections carry some of these ideas, but this one was the most impactful as a faculty member and for the work here.

For most of my life, I lived in a very privileged neighborhood. Many of the people I interacted with on a daily basis were from similar backgrounds. Getting to interact with members of the Roxbury community was a huge highlight of my first semester at NU. Robury has a reputation of being dangerous and underfunded. Just because they are underfunded and, at times, overlooked does not mean that the kids don't have the exact same potential as the rest of us. The kids I met at RIC were some of the smartest and most hard-working people (not just kids) I have ever met. On top of that, we also had multiple five and seven-year old kids at our site. You might think that five is too young to be able to grasp the basics of coding, but this was not the case. Malakai and Zion worked more diligently and were more successful than some of their older peers and Malaya helped her older sister weekly. The lesson to be learned is to never underestimate others. Your judgements of other people have no place in their lives. $\boldsymbol{E} \boldsymbol{G}$

These quotes help to build on the survey data and reinforce the concept that these students are truly finding connections in the community and seeing the community in what might be considered a new light. They see the children they work with as just that, children, who are easily distracted, frustrating, fun, smart, et cetera. They see that these children are from families that are excited about what their kids are learning. Even if this community and these children might not be in the same situation as our students may have grown up in, and it is likely they are not, that is rarely a focus of their reflections unless we ask. 


\section{Conclusion}

Through this work, we see that S-L does help our students grow their concept of community. Firstly, very few students reported that they knew the same or less about the community after S$\mathrm{L}$ and many of the negative perceptions surrounding an urban community were diminished. The majority of students clearly saw the community differently, and they interacted with community more to the extent that they now knew people there and would frequent businesses there. Through reflection assignments, we were able to ascertain more detail as to the exact connections students made with the community and see the growth they achieved. Students saw the surrounding community members as people; they changed their language in reflections from THOSE kids to THE kids.

We titled this paper with two parts, the second being "putting faces to a community to create better engineers." When we say better engineer we mean someone who has better professional skills, a more open attitude, and someone who can grow from their experiences. In an urban environment, there are many challenges to our students. For example, the neighborhood is still a part of the city where it is important to keep your wits about yourself. However, the rumors and general opinions of the area around the university go far past this understanding, and often involved hidden racial and socioeconomic prejudices. It is important to us that our students are able to distinguish personal safety concerns from their interactions with actual people. On a positive note, after S-L the students start to lose the concept that the surrounding urban community is distinct from university community. We conclude that S-L can provide an important learning opportunity to force our students out of their perceived comfort zone, helping them to grow as engineers with open attitudes who are better prepared for future challenges. 


\section{References}

[1] S. Freeman and C. Scianna, "First-year Engineering Student Expectations and Experiences: Community, College, and Curriculum," in Proceedings of the American Society for Engineering Education Annual Conference, Salt Lake City, 2018.

[2] S. Freeman, J. Love and D. Sullivan, "What Sticks with First-Year Engineering Students and Engineering Faculty in STEM Education Service-Learning Projects?," in Proceedings of the American Society for Engineering Education Annual Conference, San Antonio, 2014.

[3] K. Shannon and J. Schuman, "Engagement in Practice: Developing a Sustainable K-12 Outreach STEM," in Proceedings of the Annual Conference of the American Society for Engineering Education, Salt Lake City, 2018.

[4] M. Manuel, "Engagement in Practice: STEM Engagement through Mentoring," in Proceedings of the American Society for Engineering Education Annual Conference, Salt Lake City, 2018.

[5] D. Lieberman, "The Leap Challenge Blog," Association of American Colleges \& Universities, [Online]. Available: https://www.aacu.org/leap/liberal-education-nation-blog/rethinking-how-weperceive-and-approach-service-learning.

[6] J. Eyler, D. E. Giles, C. M. Stenson and G. C. j, At A Glance: What We Know about the Effects of Service-Learning on College Students, Faculty, Institutions and Communities, Omaha: Higher Education, 2001.

[7] G. Ngai, S. C. F. Chan and K.-p. Kwan, "Challenge, Meaning, Interest, and Preparation: Critical Success Factors Influencing Student Learning Outcomes from Service-Learning," Journal of Higher Education Outreach and Engagement, vol. 22, no. 4, p. 55, 2018.

[8] G. Kuh, "High-Impact Educational Practices: What they are, who has access to them and why they matter," AAC\&U, Washinton, DC, 2008.

[9] S. E. Henry and M. L. Breyfogle, "Toward a New Framework of "Server" and "Served": De(and Re)constructing Reciprocity in Service-learning Pedagogy," International Journal of Teaching and Learning in Higher Education, vol. 18, no. 1, pp. 27-35, 2006.

[10] L. E. Pelco and C. T. Ball, "Identity Status, Service-Learning, and Future Plans," Journal of Higher Education Outreach and Engagement, vol. 22, no. 3, p. 103, 2018.

[11] M. Sandy, "Community Voices: A California Campus Compact study on partnerships," San Francisco, 2007.

[12] S. S. Budhai and K. S. L. Grant, "First Encounters, Service Experience, Parting Impressions: Examining the Dynamics of Service-Learning Relationships," Journal of Higher Education Outreach and Engagement, vol. 22, no. 3, p. 69, 2018.

[13] D. Simonet, "AmeriCorps* VISTA, Service-Learning and Academic Success: The Links to Retention Research," Minnesota Campus Compact, Minnesota, 2008.

[14] T. Kennedy and L. Houghtalen, "Engagement in Practice: Lessons Learned While Developing Community Partners (and a New Engineering Program) for Service Learnin," in Proceedings of the American Society for Engineering Education Annual Conference, Salt Lake City, 2018.

[15] W. Oakes, E. Coyle and L. Jamieson, "Curriculum, EPICS: A Model of Service-Learning in an Engineering," in Proceedings of the American Society for Engineering Education Annual Conference, St. Louis, 2000.

[16] W. Oakes and M. Thompson, "Integration of Service Learning into a Freshman Engineering Course," in Proceedings of the American Society for Engineering Education Annual Conference, Salt Lake City, 2004. 
[17] J. Duffy, E. Tsang and S. Lord, "Service-Learning in Engineering: What, Why and How?," in Proceedings of the American Society for Engineering Education Annual Cpmferemce, St. Louis, 2000.

[18] M. Thompson and W. Oakes, "Using Service-Learning to Integrate K-12 Outreach into a First-Year Engineering Program," in Proceedings of the American Society for Engineering Education Annual Conference, Chicago, 2006.

[19] R. Rupnow, K. Davis, R. Johnson, E. Kirchner, J. Sharma and S. Talukdar, "Service experiences of undergraduate engineers," International Journal of Research on Service-Learning and Community Engagement, vol. 6, no. 1, 2018.

[20] R. G. Bringle and J. A. Hatcher, "Implementing Service Learning in Higher Education," Journal of Higher Education, vol. 67, no. 2, 1996.

[21] J. W. Eby, "Why Service-Learning is Bad," 1998.

[22] D. J. Maurasse, Beyond the campus: how colleges and universities form partnerships with their communitie, New York: Routledge Publishing, 2001.

[23] K. Carey, "Inside Higher Education," 14 October 2008. [Online]. Available: https://www.insidehighered.com. [Accessed 24 January 2019].

[24] M. D. Portsmore and J. E. S. Swenson, "Systemic Intervention: Connecting Formal and Informal Education Experiences For Engaging Female Students In Elementary School In Engineering," in Proceedings of the American Society for Engineering Education Annual Conference, San Antonio, 2012.

[25] A. e. a. Epstein, "Terrascope Youth Radio: Engaging Urban Teens in a Unique UniversityCommunity Partnership," in Proceedings of the American Society for Engineering Education Annual Conference, Louisville, 2010.

[26] M. Ratcliff and J. Fuehne, "Partnering With a Neighborhood Association to Bring Technology to At-Risk Urban Students," in Proceedings of the American Society for Engineering Education, Chicago, 2006.

[27] "Boston Public Schools," [Online]. Available: https://www.bostonpublicschools.org. [Accessed 22 September 2018].

[28] "Kids Count Data Center," The Annie E. Casey Foundation, [Online]. Available: https://datacenter.kidscount.org/data/tables/7417-free-and-reduced-price-lunch-enrollment-rates-byschool-district?. [Accessed 22 September 2018].

[29] A. Forsyth, H. Lu and P. McGirr, "Service Learning In an Urban Context: Implications For Planning and Design Education," Journal of Architectural and Planning Research, vol. 17, no. 3, pp. 236-259, 2000.

[30] S. Elwood, "Experiential Learning, Spatial Practice, and Critical Urban Geographies, Journal of Geography," Journal of Geography, vol. 103, no. 2, pp. 55-63, 2004.

[31] H. Giroux, Pedagogy and the Politics of Hope: Theory, Culture, and Schooling: A Critical Reader, Boulder: WestviewPress, 1997. 